\title{
Guiding adults impartially: $A$ Scottish study
}

\author{
GRAHAM CONNELLY \\ TED MILBURN \\ SANDY THOMSON \\ University of Strathclyde, United Kingdom \\ RICHARD EDWARDS \\ Open University, United Kingdom
}

In Scotland, the development of guidance for adults has been significant in the last few years. A 1992 Inspectorate report concluded that: 'Considerable progress has been made in developing effective arrangements for student guidance' (SOED, 1992: 36). However, the same document also called for improved pre-entry guidance and better course induction, the development of policy statements on guidance, and the commitment of resources to improving facilities, staff training and advocating. Since 1993, the Scottish Office-backed Adult Guidance Initiative-Scotland (AEGIS) has been responsible for raising awareness about good practice in guidance, and has produced policy documents and staff development materials on quality assurance and networking and held a number of national conferences. Researchers at the Scottish Council for Research in Education published four major studies in 1993-4, describing the experiences of adult returners, patterns of progression in postschool education and adult guidance practice. In 1996, the Scottish Office published strategy proposals for adult guidance, to include a telephone helpline (SOEID, 1996). TI1 is was followed by an action plan on lifelong learning and guidance, including support for local guidance networks and increased marketing of learning opportunities (SOEID, 1997a and 1997b). Further research reports on the provision of guidance as part of access to higher education in Scotland were also published in 1996 (Blencowe et al, 1996; Blair and Tett, 1996).

This article is based on research carried out to investigate the extent to which the principle of impartiality is perceived to be relevant and applicable by guidance practitioners in their work with adults. Guidance professionals have drawn attention to the importance of impartiality as a basic principle governing their practice. Also, the imperative of giving adults information and advice which is impartial and not influenced, for example, by recruitment targets for courses, is stressed in statements of good practice and practitioners' charters. The person-centred counselling approach underpinning these statements and charters tends to be strongly 'non-directive'. Guidance services have developed considerably in the last few years, but there is increasing competition between course providers and this has raised concerns about jeopardising impartiality. 
The provision of guidance which is impartial and not unduly influenced by the needs of any particular providers to recruit students has depended largely on the development of services which have emphasised communication and co-operation between agencies and workers. Prior to 1993, this was evident in Scotland in region-wide development plans for further and community education prepared by education authorities. These set out policies and standards for adult guidance practice. Guidance networks were established in some areas to encourage sharing of information and resources and to ease referral of clients, as well as to provide joint staff development initiatives.

In April 1993, further education (FE) colleges were placed outside the control of regional education authorities. Joint planning and sharing amongst neighbouring establishments and between colleges and other provision for adults tended to become agency initiated activities, although in some areas a degree of central co-ordination has been maintained. In 1996, structural changes caused by the reform of local government resulted in difficulties in maintaining lines of communication, and there was uncertainty about the funding and co-ordination of guidance networks. However, in March 1997, the government announced funding of six million pounds over three years to support developments in lifelong learning, including guidance. Much of this funding has been used to establish a free telephone helpline and 17 adult guidance networks covering the country

As well as creating changes within the organisational structures of guidance, there seems also to be an unsettling effect on the professional ethos of guidance workers, expressed in concerns over the loss, potential or otherwise, of impartiality. The professional culture of workers in the field has also changed significantly. Staff in FE colleges have been debating how guidance responsibilities should be shared between subject teachers and specialist counsellors. Though this is not a new issue, it does appear to be having a broader and more open hearing. Careers officers, long viewed as the independent, 'honest brokers' of the educational world, have been recruited to work in colleges and assigned to Local Enterprise Company projects, where their impartiality may be not quite so clearly defined. Community education workers are no longer just organisers of courses, but have found a wider role supporting adults in their first tentative steps in education, called on to give detailed impartial advice about progression opportunities and potential employment options.

\section{Impartiality in guidance: the background}

The practice of providing guidance to adults in connection with education, training and employment has developed considerably in the UK since the early 1980s. The development of recognised standards of provision owes much to the work of the Unit for the Development of Adult Continuing Education (UDACE, 1986). This described educational guidance for adults as a process involving seven separate activities (informing, advising, counselling, assessing, enabling, advocating and feeding back) and also argued that work with adults should be conducted within a framework of general principles. Guidance should be client-centred, confidential, open to all adults, accessible, independent, publicised widely and able to contribute to the development of learning opportunities.

The term impartiality does not feature specifically in the UDACE principles, though it is clearly implied in the use of the terms client-centred and independent. The words 
'impartial' and 'impartiality' - meaning 'unprejudiced' or 'fair' or 'equal treatment' feature in a number of important policy documents and research reports. For example, the Institute of Careers Guidance (1CG) and the National Association for Educational Guidance for Adults (NAEGA) published a joint statement in which they declared that guidance should: '.. be independent of the interests of any supporting agency or institution. . .', and, '... be delivered by trained advisers whose competence and impartiality can be proven...' (1CG/NAEGA, 1992). The Higher Education Quality Council has drawn attention to the complexity of relationships between impartial guidance, which they describe as 'learner-centred', and what they call 'provider centred' admissions to higher education (HEQC, 1994). In these documents the impression is given that impartiality in guidance is achieved where practitioners are

concerned with the expressed needs of the client making an enquiry or seeking help, and where the individual can expect to receive a service comparable to other clients. In this approach impartiality is viewed as being synonymous with 'client-centred' behaviour.

However, other factors may influence the guidance given to adults. In a research report on adult guidance in Scotland, the authors identified a policy issue arising in one of their case studies, a regional adult guidance unit, where they observed:

... advocacy can cause tensions with education providers who may be funded on the basis of student numbers and therefore place priority on getting students into courses and sometimes overlook whether courses suit individuals' needs. (Lowden and Powney, 1993: 49)

The same study attempted to gauge clients' perceptions of providers' qualities. One of the qualities checked was the ability to provide 'unbiased' guidance. $87 \%$ of the sample of 138 students thought this applied to their guidance provider. There is an apparent contradiction in these two findings, unexplained in the report. However, companion research offers one possible explanation:

Although 34 respondents reported that they were satisfied with the guidance they had received, many of these never received any help other than a prospectus through the mail or a chat with the switchboard. Yet for most adults, this was enough, because they had neither expected more nor were aware that anything else might be available. (Blair et al, 1993: 54).

The implication of this observation is that adults could be recruited happily into courses without pre-entry guidance to help clarify their educational needs and evaluate the provision.

An important source of guidance for adults is the help they receive from friends and relatives. Blair et al (1993) found this was the only source of guidance for over half their respondents, and offer a number of reasons for this, including the fact that adults need to feel they can trust their adviser. Trusted friends or family can offer guidance knowing a great deal about the prospective student. However, few friends or relatives will have wide knowledge of educational opportunities which hints at another potentially important aspect of impartiality - the extent to which the guidance offered by guidance workers is complete and wide-ranging.

These two features of impartiality, client-centredness and completeness of information may be in tension to some extent. This is best illustrated by the distinction between the humanistic model of guidance which emphasises the 
worker's role in helping the client to understand his or her needs and an information processing model which views guidance as the provision of information from which rational choices are made. In the latter approach, the focus may be more on the information and the increasingly sophisticated technology used to access it, and less on the client, or on the interaction between client and guidance worker. This may well also reflect the differences in the perceptions of what is required from guidance among clients and professional workers - the former with a more pragmatic expectation than the latter.

\section{Method}

We began with a hypothesis that practitioners from a range of organisational settings and reflecting differing agency philosophies and professional training would have varying perspectives of impartiality, and that these differences would, in turn, influence guidance practice. We wanted to establish the meanings which practitioners placed upon their day to day experiences with adults in guidance contexts, to understand the constraints and opportunities upon impartial behaviour within different agencies and those which derive from personal-professional belief systems and exposure to professional training. Since we could not assume a single shared definition of impartiality, we chose ethnographic methods to uncover the range of meanings which influence practice (Hammersley and Atkinson, 1983).

Using the conceptual analysis methods popularised by Wilson (1963), we conducted an initial brainstorm about impartiality and related concepts. We shared views about instances of guidance which seemed to qualify as impartial and those which did not. For example, a college-based guidance worker who advised an enquirer that the course he was interested in could also be studied in neighbouring schools, a competitor college and by distance learning, would be offering impartial guidance. Encouraging a 35 year old woman to consider courses in caring entirely on the basis of her experience in raising children would be to deny her individuality and broader interests. Our discussions helped us to identify tentative 'impartiality variables', factors which could determine the extent to which guidance might be perceived to be impartial. These are shown in Table 1 below.

Table 1: A tentative model of impartiality variables

\begin{tabular}{|ll|}
\hline Variables & Illustrative Example \\
\hline Social/political & Extent of competition between providers. \\
\hline Organisational & Whether or not an agency is in a 'guidance network.' \\
\hline Worker-related & Influence of training and professional ideology. \\
\hline Client-related & The extent of the client's assertiveness. \\
\hline Implementation-related & $\begin{array}{l}\text { Moving from recognising impartiality as a worthy } \\
\text { principle to active practice by, say, referring to } \\
\text { other agencies. }\end{array}$ \\
\hline
\end{tabular}


We used the focus group method (Morgan, 1990) in order to conduct an initial survey of practitioners' ideas relating to impartiality and contextual factors which limit or facilitate impartial behaviour. Guidance practitioners from a broad range of guidance settings were invited to join us in the summer of 1995 for a discussion on 'Impartiality in Adult Guidance'. These were: two further education lecturers with extensive guidance responsibilities; two former careers officers now working in further education colleges; two community education workers; a careers officer; a guidance worker employed by a private company; and two workers from different guidance networks. No attempt was made to achieve 'representation' in this sample, but we were careful to ensure typicality through the choice of work settings from which

participants were drawn.

- The discussion produced a number of identifiable themes. These were:

- the conflict in FE colleges between written commitments to client-centredness and pressures to satisfy admissions targets or to hold on to good students and recruit them for higher level courses;

- the overlap between guidance and marketing roles;

- the blurred distinction between guidance and selection;

- equality of treatment;

- the variable extent to which providers get involved in guidance networks and other forms of co-operation;

- the widely different perceptions of guidance held by managers;

- differential access to databases and other detailed information sources;

- the different experiences of practitioners working in different contexts.

To examine these issues in more detail, as well as explore the different perceptions of impartiality held by practitioners, we identified a pool of potential interviewees, selected because of their substantial knowledge of the adult guidance context - some of whom had participated in the focus group seminar - and finally conducted interviews with twelve practitioners. Three of the interviewees worked in separate further education colleges (two guidance managers and one departmental guidance adviser), four were staff from community education settings, and two were careers officers with adult guidance responsibilities. We also interviewed an organiser with a voluntary sector adult education project, a Citizen's Advice Bureau manager and a guidance worker from a Local Enterprise Company. Interviewees came from different parts of Scotland, not to ensure complete geographical representation, but to avoid being unduly influenced by the local characteristics of one area.

Interviews were conducted in the summer and early autumn of 1995 and typically lasted for 45-60 minutes. They were tape-recorded to avoid distractions associated with notetaking. Respondents were promised that neither they nor their agencies would be identified in subsequent reports of the findings. We devised a standard format and used semistructured interviews for ease of comparison of results.

\section{Emerging issues}

A number of issues or observations have emerged which seem to offer important clues in understanding the tensions arising for practitioners as a result bf the interplay of professional values, institutional imperatives and practical realities in the provision of impartial guidance. 
Issue 1: Impartiality has different meaning for different guidance workers and those operating in different contexts.

When asked about their understanding of the concept of impartiality, most of our interviewees referred to ideals commonly listed in guidance charters and mission statements. Examples of these are: helping people to reach informed decisions about their future, based on gathering together information about a range of options; giving unbiased information which is not linked to the needs of one provider or the worker's own livelihood; behaving in a client-centred manner so that the adult's best interests are considered. One careers officer described her work as 'trying to guide a client through all the aspects and avenues'. In her guidance work with clients she aimed: , ... to try and raise the questions for them in the sense of helping themselves look at issues, all brought together by helping that person make their own decision without ourselves colouring it' .

Probing the concept further revealed differences in the perceived meaning of impartiality, associated with the different contexts in which guidance is offered. The careers officers, for example, tended to hold the view that impartiality followed from three characteristics inherent in their service: first, not being direct providers of courses or jobs and therefore having no recruitment targets to meet; second, having access to comprehensive information about occupations and educational opportunities; and, third, having typically experienced training which emphasises the non-directive or person-centred approach in working with clients. In practice, there are complicating factors which spoil this view of impartial guidance. Although having access to extensive information, careers officers know more about some opportunities than others, or have formed favourable views from their relationships with one provider compared to another. However, unwittingly, these 'hidden persuaders' are likely to influence the guidance given. This raises questions about the basis of this selection, and the importance of making explicit the criteria used in the selection process - questions about the assessment process which were beyond the scope of this investigation.

Community education workers and those working in voluntary adult education and guidance projects have a lot in common. In the main, guidance is given in the context of helping adult returners to develop personal confidence and basic skills. These workers tended to speak about impartiality in terms of 'empowering' adults to evaluate information from different sources. Often this is a gradual process, developing out of an educational experience itself. 'You are working with them so that they are enabled to make the choices or come to the decisions that will suit them for their future direction'. Community education workers typically describe guidance embedded within a programme, rather than a 'bolt on' extra. They also have fears about not being able to provide adequate information and being extremely limited in the amount of time they can offer to individuals to help them make sense of their current studies or consider further educational and vocational options.

Guidance staff in FE colleges were most likely to talk about factors which limit their ability to give impartial guidance. All our FE interviewees were aware of pressure to fill courses: 'We are selling our courses, that's the dilemma'. The distinction between internal and external impartiality arose in these discussions. College staff striving for good practice could guarantee to give factual information about competing courses within their college, and to treat all students with the same degree of respect. However, loyalty to the employing institution made it difficult, or unreasonable, to expect staff to 
recommend competitors' courses, or to encourage potential students to consider other options - at least at the pre-entry stage. Our respondents were not aware of direct injunctions from college senior managers to avoid mentioning courses available elsewhere. It was rather that an assumption was made that there was a pre-determined interest in following an appropriate course in that college.

Two situations were identified when it appears to be easier for college staff to be more impartial in the sense of giving information about opportunities available elsewhere. First, if it emerged that an enquirer was seeking a course not available in the guidance worker's own college, other options could be legitimately raised. Second, at the pre-exit stage a range of progression opportunities could be discussed. However, the increasing tendency to provide higher level courses in the further education sector meant colleges understandably wished to develop an internal market and encourage students to remain and progress within their current institution.

Careers officers tended to take a pride in their service as the 'honest brokers', people with 'no axe to grind' who could more easily 'put the client first.' Community education staff are proud of their role in general confidence-building and awareness raising with adults returning to education for the first time. In the eyes of these respondents, the easily identified villains were FE college staff. They were perceived as being interested only, or mainly, in 'bums on seats', and therefore particularly likely to want to steer enquirers in the direction of their own courses. This was borne out by the FE respondents who reported incidents where staff who were not guidance specialists had been vigorously recruiting students into their own departments. FE guidance staff could relate experiences of their attempts to offer an impartial service being frustrated by colleagues' overriding concern with recruitment.

However, it also appeared that practitioners often define their own practices in relation to the perceived partiality of guidance provided elsewhere. This provides the possibility for a certain lack of critical reflection in relation to their own practices and, on occasions, a certain moral grandstanding. A more considered approach was offered by one interviewee: ' ... you might have very laudable ethics.. . but it's only as impartial as the information you have, so you might just have a very incomplete picture and be offering it impartially, but it's not the full picture'. This awareness of the guidance worker's limitations appears to be a necessary health warning: only by acknowledging such limitations can guidance workers provide an honest service.

\section{Issue 2: Guidance workers may feel torn between their personal beliefs about what constitutes impartial guidance and the expectations of the organisation which employs them. Also, within institutions more junior guidance staff-and guidance specialists in general-may not feel in a strong position to argue in favour of the importance of impartial behaviour.}

Several writers have referred to the stresses caused by 'cognitive dissonance' (Festinger, 1957) when an individual has to reconcile two apparently contradictory sets of beliefs. There was clear evidence of this in the responses of some of the interviewees, who felt a professional obligation to be 'client-centred', while working within an organisation with different priorities. Nowhere was this more marked than in the comments of one member of the focus group, a qualified careers officer now employed in a FE college. Her perception of her situation was that she felt obliged to direct enquirers to the best available educational provision, while being aware that her employers assumed that her 
function was to locate students into the most appropriate course within that college. While this did not always represent a conflict, it did so sufficiently often to cause considerable negative feelings about the college and her situation. However, there is also evidence that some FE colleges are developing sophisticated approaches to marketing, characterised by an awareness of the undesirability of recruiting students inappropriately who later leave courses prematurely.

The degree of cognitive dissonance appears to depend on the guidance worker's position within either the formal or informal power structure of the organisation. Where guidance workers are relatively junior members of staff, or where they have few allies in more powerful positions, they seem likely to experience more difficulties in operating impartially. Conversely, the support of senior management is perceived by guidance workers as a crucial determinant of good guidance practice, in which impartiality is seen to feature prominently.

There may be nothing illegitimate per se in college managers expecting guidance staff only to supply information about courses in their own colleges. To fulfil certain performance indicators, community education workers or staff of training organisations may feel under pressure to meet targets or fulfil quotas by encouraging clients towards their own provision. It may be unrealistic to expect guidance staff employed by one provider to carry equal supplies of information, or to be as well informed personally about the courses offered by competitor organisations. This is not to say that a full knowledge base is both a necessary and a sufficient condition for impartial guidance. While it helps to know something about opportunities outwith one's own organisation, that wider knowledge will not guarantee impartiality in the absence of an organisational agreement about sharing knowledge with the client. Networking has an important part to play, and referral is rightly signalled as a key professional competence of guidance staff. However, referral is more likely to occur in situations where guidance workers know that their own organisation has nothing to offer the client and hence has nothing to lose by referral.

An obvious consideration is the influence of staff training. All the interviewees were trained to some extent in adult guidance, and most were either undertaking or had completed advanced training. We collected anecdotal evidence of poor or incomplete guidance where workers had no specialist training, yet it is much too simplistic to suggest that partial guidance is related, in whole or part, to a lack of training. Trained workers know that impartiality is a principle which guidance professionals regard as important. However, that knowledge in itself cannot protect against students being recruited onto courses without being encouraged to consider alternative options.

\section{Issue 3: Guidance which is clinically impartial, objective and free from opinion may not always be perceived by clients as being in their best interests and, indeed, adults may expect a more judicious approach from professional workers.}

Several respondents argued that impartial guidance was not necessarily what clients either expected or wanted. If, for example, clients choose to visit a particular college to seek information about courses of study, they are unlikely to expect to be given details of courses on offer at a different college. One respondent used the analogy of the car showroom. You don't turn up at a Volkswagen dealer expecting guidance about buying a Ford. According to this viewpoint, supplying 'impartial' guidance has the potential to both puzzle and irritate the enquirer. 
One respondent, working in a voluntary sector agency, described how she recommended courses in a particular college because she had received good feedback from past clients and furthermore, she had invested time in developing close professional relationships with college staff. She was aware this preferment ran counter to values she considered important - and indeed differed from the general advice given to prospective students to 'shop around' and evaluate a range of possibilities - but rationalised this tension on the basis that adult learners benefited from her good relations with the college. Many such preferential arrangements exist, where it is understood that adult learners completing a community-based course who wish to progress will enrol on courses in the local college. Further, it is only in the larger urban areas that there is any real choice of provider for many adult learners who need to study close to their domestic commitments. It is not simply the case therefore that agencies not providing learning opportunities are more impartial in the guidance they give.

An over-simplified equation of 'impartiality' with 'client-centredness' cannot be sustained. Providing the most beneficial service to the client may well involve being 'partial' - such partiality being based on the guidance practitioner's experience and understanding of the relative strengths and weaknesses of different service providers. The neutrality implied by a non-directive approach to guidance is often the method of choice, but the client may be unprotected against clever marketing by course providers, and disadvantaged by lack of clarity about their own interests. One interviewee, a community education worker, argued she was being impartial when she was challenging clients to consider raising their aspirations and look at a wider range of opportunities. There are risks, of course, for professionals stepping outside the role of detached 'counsellors', such as making incorrect assumptions about the client's needs, or basing guidance on out of date information about particular courses, service

providers or employment opportunities. A careers officer commented:

'People may come in to speak to us and they have a tunnel vision approach to the options. . . based on the media experience, what other people tell them. . . and they are very much influenced by this. People say, someone has told me I should do this, what do you think about that?.. Until people know the range of options open to them then they cannot make informed decisions - they'll make decisions based on imperfect information:

Guidance workers rarely meet clients who are totally devoid of any preconceptions about the opportunities open to them. The encounter with a guidance worker commonly takes place a reasonable distance along a path which may have begun with vague feelings that life had more to offer, had progressed through discussions with family and friends, and may even have involved earlier encounters with other agencies or organisations. In these circumstances, it is unlikely that guidance workers will give equal weight to all the options available. Rather they may want to encourage the client to consider alternative options in order to ensure that decisions eventually taken are based on an adequate supply of information and a full understanding of pros and cons. In other words, they are partial in their guidance as a counter-balance to the partial information previously available to the client.

It would be dangerous for guidance workers to assume that information from family, friends, the media and press are necessarily partial while their own approach is totally impartial. Friends and family have a better prospect of knowing the advice-seeker well. Guidance workers are disadvantaged by not knowing the client well and depending on information often given during a single interview. However, careers officers routinely 
follow up interviews with written summaries, which give the possibility of including suggestions and information based on further consideration. Community education workers and other on-programme guidance staff are in a position to develop relationships with individuals, which can be helpful in tailoring guidance.

Issue 4: Unequal power relationships between guidance worker and client may militate against impartial behaviour.

A degree of equality in the contractual relationship between lecturer/worker and adult learner may be necessary to offer a good guidance service. One view of impartiality is that it involves objectivity achieved by careful attention to the facts available from a client's referral documentation and by interview, and also the possible use of psychometric tests. However, this view of the worker seems to put the professional in a position of power, directing the transaction by requesting personal information, issuing forms to be completed, structuring the interview and defining the guidance process. Concerns about this kind of inequality between the worker and client were raised by interviewees from community education settings, who spoke of the importance of guidance becoming an integral part of the tutorial relationship.

'Expert knowledge', the combination of considerable experience in providing guidance to adults in vocational and education aspects of their lives, and access to extensive resources and local information and contacts, is important. 'If they [adults] have poor decision-making skills, then they really want you to narrow the options for them'. The issue then reduces to one of the level of confidence which a client has in knowing his or her own wishes, expressing these clearly and guarding against being 'nudged' in a particular direction due to the limited range of opportunities available.

Most respondents assumed impartiality is about being impartial between providers - of jobs, education or training. Impartiality, however, also concerns the perceived obligation to be impartial between clients - not to discriminate between them in the delivery of the guidance service. It is difficult to understand why this received so little

attention. Is it because it is somehow taken for granted that professional guidance staff do not discriminate? If the job of the guidance worker is seen as 'matching' clients with opportunities and vice versa, then both aspects of impartiality appear to be equally important. 'It's not about treating people the same. People don't need to be treated the same; they don't want to be treated the same'. To provide fair and equal guidance may involve treating people differently to take account of issues such as class, gender, 'race' and ability.

A careers officer initially said that an example of partial guidance was not treating everyone the same, then acknowledged this approach risked perpetuating stereotypes. She gave an example of a guidance interview with a black woman who suffered from epilepsy. She realised her care to avoid discussing the woman's ethnic background avoided an important aspect of that client's identity. 'I did that person a disservice. I wouldn't do it again. I would deal with it.'

\section{Discussion}

Early discussions with practitioners uncovered considerable fears about the supposedly deleterious impact of introducing marketing approaches within further education following the incorporation of colleges. These fears were expressed by college guidance practitioners, concerned that their ability to remain relatively independent of 
funding and recruitment considerations might be threatened. They were also expressed by careers officers and community education staff, often highly critical of FE colleges for supposedly putting recruitment before individual needs. Subsequent interviews indicated that this is a more complex issue. One effect of a more market-led approach is that colleges tailor their portfolio of courses to match market demand. In one sense, this is liberating, and also exactly what community educators say they do in meeting local needs. But courses have to be cost-effective and this may narrow the choice of provision, and thereby limit the extent to which a full range of local needs can be met.

Education professionals tend to speak of marketing pejoratively. However, some of our interviewees pointed out that reaching out more effectively to students through advertising on local radio and paying careful attention to the design of course information and offering permanently staffed drop-in advice centres can help to make colleges more 'client-centred', one definition of impartial guidance.

Adult guidance workers face difficulties when aware of differences in quality between providers. A common response is to brief the client on how to interrogate the education/training provider. One interviewee said he might use this form of words: 'All I can suggest to you is that you go and ask some searching questions, like, "What am I getting for my money? What happened to the last batch of trainees that went through that process? Can you name one organisation that respects the bit of paper you get at the end of the course?"'.

Impartiality is trumpeted as an important principle in guidance charters; it is clearly important to workers, but is it important to clients? The answer is not clear, but we would suggest it depends on the circumstances. The notion of impartiality often is sustained by workers being able to point to its absence in the practices of other agencies. This cannot be an entirely satisfactory justification. The notion of impartiality as client-centredness is seen in its most positive expression where community workers engage in a partnership with clients to explore options as part of a learning exercise. However, the call for FE colleges to provide this kind of impartial service in their advice centres may be misplaced in its assumption of client vulnerability. It is unlikely that the majority of clients walking into a college expect to receive information about courses elsewhere. Indeed that may produce puzzlement: 'Sometimes if you start saying, "Oh, you can do that elsewhere", they think you're not interested in them, or that you're saying, "Oh you're not suitable for college".'

The suggestion made at the start of our investigation was that the extent to which guidance was perceived as impartial depended on a range of variables. These were categorised as social/political, organisational, worker-related, client-related and implementation-related. The issues identified in this study can be related to these variables in the following way.

Social/political variables include two related aspects of currently dominant ideology. First, the emphasis on competition between providers of education, training and guidance services. Second, the corresponding encouragement to clients of these services to define themselves as customers or consumers, shopping around between various service providers. The first emphasis is embodied in the incorporation of FE colleges and the removal of careers services from local authority control. The second aspect shows in support for student charters and voucher schemes. Among our interviewees, guidance staff in colleges were probably the most aware of and most affected by these developments. However, all interviewees seemed conscious of the 
range of players operating in the guidance field, and of the consequent atmosphere of uncertainty surrounding the future of their own particular services.

Organisational variables include the availability or accessibility within the organisation of information about education and training opportunities. Careers officers felt that an important safeguard of their impartiality lay in a plentiful supply of college and university prospectuses and details of local training programmes. Active membership of a guidance network or adult education forum was also highlighted as a factor which encouraged impartial guidance. However, it was also clear that some aspects of an organisation could be perceived as operating against impartiality. College-based workers described a situation at the pre-entry guidance stage in which their own efforts to be impartial were effectively negated by subject departments engaging in recruitment at all costs. Pressure of time due to staffing restrictions was also seen as inhibiting impartial practice.

Worker-related variables are evident throughout this study, particularly in respect of professional ideologies and ethical codes. Interviewees were at least conscious of what were perceived to be obligations towards their clients. To what extent these perceptions resulted from professional training or from the culture of their work was outside the scope of this study. However, notions of 'empowerment', 'client-centredness' , 'non-judgmentalism' and 'impartiality' were frequently invoked. Cognitive dissonance was greatest when individual ethics appeared to conflict with organisational demands.

Client-related variables are less frequently mentioned, with the striking exception of the Citizen's Advice Bureau manager, who was concerned about the need to be impartial between clients rather than between different service providers. Dependent on volunteer guidance workers, she was particularly aware of preconceptions about client types - as 'scroungers', etc. - which could result in unequal or inappropriate provision of help. On reflection, it is difficult to understand why more of our interviewees did not raise this as an issue.

Implementation-related variables helped us to separate factors affecting a stated commitment to, or belief in, impartial guidance, from factors affecting actual guidance practice. Almost all of the issues discussed in relation to the first four variables are relevant in this respect and have tended to obscure a convenient distinction of this nature.

\section{Conclusion}

This study suggests that adult guidance practitioners generally are concerned about their obligations to give impartial guidance. Some will have given careful thought to both the importance of impartiality and its practical applications. These are likely to be practitioners who are aware, for example, that: being impartial in respect of the different options available could bring them into conflict with other parts of their organisations, or other aspects of their roles; that being 'client-centred' and being 'impartial' are not necessarily the same thing; that clients may arrive with their own preconceptions, which will require to be addressed; and that impartial guidance does not simply consist of supplying clients with as much information as possible.

Interviewees also suggested advice for providing impartial guidance. For example: being impartial can have more to do with the nature of the worker-client interaction than with the supply of information available; impartial guidance might involve 
equipping clients with the questions to ask opportunity providers; rather than engaging in a fruitless pursuit of 'perfect impartiality', guidance workers should content themselves with a commitment to declare openly the limitations of their ability to provide a full and impartial service, a kind of guidance 'health warning'.

Impartiality is clearly an important principle in guidance work with adults. As one interviewee put it:

The context in which advice is given has to be seen as impartial. The giver of advice shouldn't be seen to benefit from that advice. There should be no evidence of selfinterest or self-seeking by the giver of advice.

However, the assumption that because workers feel impartiality is a good thing in guidance it will happen is not warranted. This confirms research on pre-entry guidance in FE colleges reported elsewhere (Payne and Edwards, 1997). In their study of 12 FE colleges in England, Sadler and Reisenberger (1997: 28) found that a commitment to impartiality could be written into policy 'without any indication as to how this is to be monitored and without an agreed understanding, across the institution as to what it actually means'. Also, 'perfect impartiality' is often unattainable for good practical reasons. Feelings amongst practitioners about the importance of the principle of impartiality in adult guidance are sustained by a view of others as behaving partially. This view is unfair because it is based on rather simplistic assumptions about the transactions between clients and workers. The view that impartiality is compromised by the arrival of new market principles in post-school education is also not entirely supported.

The fieldwork for this study was conducted in 1995. Whether the situation has changed and in what ways in 1998 requires further study. It is one of the constant tensions in empirical research that the reporting of it is generally after the event, by which time, practice may well have moved on, or it will be claimed to have moved on - tactic often used to deflect critical commentary by policy-makers and managers. In general, more research in this area is called for, particularly to observe the effect of different funding arrangements on the tensions observed between course selectors and guidance practitioners. The argument that the funding arrangements of colleges has been a disincentive to impartial guidance requires close examination. This study also points to the need to explore more fully the different perceptions of guidance workers in different contexts. The implications of local government changes and devolution in Scotland also need to be examined.

\section{Note}

This research was funded by the Centre for Educational Policy and Management, School of Education, Open University and the Faculty of Education, University of Strathclyde.

\section{Bibliography}

Blair, A. and Tett, L. (1996). Options and Choices: Access, Guidance and Support for Adults in Higher Education, Mapping Study, Edinburgh: Moray House Institute of Education, Heriot-Watt University

Blair, A., McPake, J. and Munn, P. (1993). Facing Goliath: Adults' Experiences of Participation, Guidance and Progression in Education, Edinburgh: SCRE

Blencowe, L., Denning, P. and Tett, L. (1996). Adult Education Guidance in Higher Education: An 
Investigation of Guidance Systems with Three Institutes, Edinburgh: Moray House Institute of Education, Heriot-Watt University

Festinger, L. (1957). A Theory of Cognitive Dissonance, Stanford,CA: Stanford University Press

Hammersley, M. and Atkinson, P. (1983). Ethnography: Principles in Practice, London: Tavistock

HEQC (1994). A Quality Assurance Framework for Guidance and Learner Support in Higher

Education, London: Higher Education Quality Council

ICG/NAEGA (1992). A Guidance Entitlement for Adults, Institute of Careers Guidance/National

Association for Educational Guidance for Adults

Lowden, K. and Powney, J. (1993). Where Do We Go From Here?: Adult Educational Guidance in

Scotland, Edinburgh: SCRE

Morgan, D.L. (1990). 'Focus groups as qualitative research', Qualitative Research Methods, Series 16, Newberry Park: Sage

Payne, J. and Edwards R. (1997). 'Impartiality in pre-entry guidance for adults in further education colleges', British Journal of Guidance and Counselling 25 (3), pp 361-276.

Sadler, J. and Reisenberger, A. (1997). On Course For Next Steps: Careers Education and Guidance for Students in FE, London: FEDA

SOED (1992). Staying on Course: Student Guidance in Scottish Further Education Colleges,

Edinburgh: The Scottish Office

SOEID (1996). Adult Guidance in Scotland: Strategy Proposals, Edinburgh: The Scottish Office.

SOEID (1997a). Lifelong Learning: Summary of Responses to the Public Consultation, Edinburgh:

The Scottish Office

SOEID (1997b). Lifelong Learning: The Way Forward, Edinburgh: The Scottish Office

UDACE (1986). The Challenge of Change: Developing Educational Guidance for Adults, Leicester:

National lnstitute of Adult Continuing Education

Wilson. (1963). Thinking with Concepts, Cambridge: Cambridge University Press 